\title{
ALGUMAS PARTICULARIDADES NO ENVELHECIMENTO DO GAMETA FEMININO
}

\author{
Some particularities of aging on female gamete
}

\author{
Fernando Andrade Souza ${ }^{[a]}$, Igor Frederico Canisso ${ }^{[\mathrm{b}]}$, Jair Perez Osório ${ }^{[\mathrm{c}]}$ \\ [a] Médico Veterinário pela Universidade Estadual do Maranhão (UEMA), Mestre em Medicina Veterinária e Doutorando em \\ Ciência Animal pela Escola de Veterinária da Universidade Federal de Minas Gerais (UFMG), Belo Horizonte, MG - Brasil, \\ Bolsista CAPES, e-mail: femedvet@yahoo.com.br \\ ${ }^{[b]}$ Médico Veterinário pela Universidade Federal do Paraná (UFPR), Mestre em Zootecnia pela Universidade Federal de Viçosa \\ (UFV), Estudante de Ciência Equina - Instituto de Ciências Rurais, Universidade de Aberystwyth, Aberystwyth - Grã-Bretanha, \\ e-mail:canissoif@yahoo.com.br \\ ${ }^{[c]}$ Médico Veterinário e Zootecnista pela FZV-Cordoba/Colômbia, Mestre em Medicina Veterinária e Doutorando em Ciência \\ Animal pela Escola de Veterinária da Universidade Federal de Minas Gerais (UFMG), Belo Horizonte, MG - Brasil. Bolsista \\ CAPES, e-mail: jair_ufmg@yahoo.com.br
}

\section{Resumo}

O estádio de desenvolvimento do oócito no momento da ovulação é variável entre as espécies. Em algumas, como a equina, devido ao período de estro da égua ser longo e o momento da ovulação ser variável, caso ocorra demora na fecundação, a retomada da meiose do oócito pode ser iniciada precocemente, o que ocasiona maior incidência de mosaicismo nos cromossomos sexuais. Adicionalmente, apresenta instabilidade das organelas citoplasmáticas e nucleares, fragmentação, desenvolvimento anormal e morte celular. As causas que promovem a deterioração progressiva levam à fragmentação do oócito, mesmo na ausência de fecundação, sendo essas mudanças morfológicas resultantes da ativação de um grupo de proteases (caspases). O envelhecimento do oócito também pode acarretar o rompimento das membranas mitocondriais e/ou gerar a inabilidade de produzir adenosina trifosfato, e assim comprometer a manutenção do ovócito fecundado. O aumento da idade materna tem sido associado com a deterioração do oócito, ocasionando maior incidência de perda embrionária precoce. Os fatores e os mecanismos etiológicos responsáveis pelo aumento dos erros na distribuição dos cromossomos durante a formação das células germinativas, ainda não são amplamente conhecidos, podendo ser distribuídos entre os estádios de formação das células germinativas e meiose no embrião, estando relacionados principalmente à não-disjunção cromossômica. A atuação da aneuploidia, sobre o atraso na maturação do oócito, pode estar relacionada, principalmente, à atividade do fator promotor de maturação (MPF) e da proteína quinase mitogênica ativada (MAPK), sendo estas as causas mais prováveis do aumento da perda reprodutiva em fêmeas mais velhas. Esta revisão tem por objetivo descrever alguns dos eventos que ocorrem durante o envelhecimento do oócito nos momentos pré e pós-ovulação.

Palavras-chave: Fator promotor de maturação. Envelhecimento. Oócito. 


\begin{abstract}
The developing status of the oocyte at the moment of ovulation is variable among species. In some species, such as equine, because the estrous mare is long and ovulatory time is variable, if the fertilization occurs too late the development of oocyte could be initiated too early as a consequence of the restarting of oocyte meisois II, so raising the incidence of the mosaicism on sexual chromosomes will occur. In addition also can be present are: instability of organelles nucleates and cytoplasm, oocyte fragmentation, abnormal developing and cell death. This morphological change comes from activation of proteases groups (caspases). The age of oocyte could be cause of the rupture of mitochondrial membranes, or produce disability for generation adenosine thiphosphate and as a consequence that could be prejudicial for holding oocyte fertilized. The maternal aging has been related with decreasing of oocyte quality and increasing the rates of loss embryonic. The mechanisms and ethological factors responsible by elevation of errors on chromosome distribution during the formation of germ cells need be more clarification, however could be occur between the stages of germ cells formation to embryo meiosis, and normally is correlated with non-disjunction chromosomal. The aneuploidy major effects above the delay of oocyte maturation could be related with activity of maturation promoter factor (MPF) and mitogen activated protein kinase (MAPK), and both could be major cause for reproductive loss in elderly mares. The aims of this article review is describe some aspects involved in mammalian's oocyte aging of pre and post ovulation.
\end{abstract}

Keywords: Maturation promoter factor. Aging. Oocyte.

\title{
INTRODUÇÃO
}

Na maioria dos mamíferos placentários, o oócito, após a ovulação, tem viabilidade curta, com tempo médio de vida variando de 8 a 10 horas (HUNTER, 1990). Em algumas espécies, como na equina, os dados são conflitantes. Alguns autores registraram o tempo máximo de viabilidade do oócito equino como sendo de 12 horas (WOODS et al., 1990), enquanto que outros autores estimaram o tempo de viabilidade oocitária, pós-ovulação, ao redor de 18 horas (SALTZMAN, 1940).

O tempo de viabilidade pós-ovulação é ponto comum entre todos os estudos que envolvam a qualidade e viabilidade do oócito, pois o decorrer do tempo pós-ovulação em relação à fecundação está associado com o desenvolvimento normal do oócito, com as taxas de concepção e com a ocorrência de anormalidades cromossômicas (HUNTER, 1990).

$\mathrm{O}$ aumento da idade materna tem sido registrado estar associado com a deterioração do oócito, principalmente na espécie humana (BUKVIC et al., 2001). A redução da fertilidade em animais com maior idade, pode ser atribuída à maior incidência de perda embrionária precoce (BALL, 2000). Em humanos, este é o fator essencial de análise em gametas femininos de mulheres mais velhas, embora os mecanismos biológicos subjacentes a este fenômeno não tenham sido completamente elucidados (PLACHOT, 2003). O envelhecimento tem sido associado com o aumento da incidência de aneuploidia, que pode interferir com a formação das células germinativas nos estádios iniciais de meiose no embrião e durante o período da parada meiótica do oócito, antes da retomada da maturação (BAIRD et al., 2005).

Esta revisão tem por objetivo descrever alguns dos eventos que ocorrem durante o envelhecimento do oócito ao longo da pré e pós a ovulação.

\section{REVISÃO DE LITERATURA}

O estádio de desenvolvimento do oócito no momento da ovulação é variável entre as espécies, sendo que na canina e na equina, as diferenças são maiores em relação às demais. Particularmente, nesta 
última espécie, o estádio de desenvolvimento nuclear à ovulação pode variar entre animais e ciclos estrais, que pode ser, ocasionalmente, liberado como ovócito primário, embora seja mais frequente o estádio de ovócito secundário (HUNTER, 1990). Ainda em equinos, devido ao período de estro da égua ser longo e o momento da ovulação variável, caso ocorra demora à fecundação, o desenvolvimento do oócito pode ser iniciado precocemente, o que leva à maior incidência de mosaicismo nos cromossomos sexuais, indicativo de envelhecimento celular (BLUE, 1981). Este processo, em adição, apresenta instabilidade das organelas citoplasmáticas e nucleares, fragmentação, desenvolvimento celular anormal e morte (FISSORE et al., 2002). Estudos conduzidos em camundongos confirmam esses achados, ao se ter sido demonstrado que oócitos envelhecidos exibem características morfológicas anormais antes da fecundação, tais como: o desaparecimento da área rica em microfilamentos acima do fuso meiótico (HUNTER, 1990), rompimento e localização anormal do fuso e desorganização da cromatina (FISSORE et al., 2002).

As características que promovem a deterioração progressiva levam à fragmentação do oócito, mesmo na ausência de fecundação. Supostamente, estes eventos advêm da morte celular programada, já que a deterioração citoplasmática é acompanhada pela fragmentação de DNA, determinada pela presença da enzima deoxinucleotidil transferase terminal (TdT) (FISSORE et al., 2002), além de características típicas de apoptose, tais como: diminuição do volume celular (núcleo e citoplasma), alterações de membrana, fragmentação e condensação de cromatina nuclear e segmentação da célula em corpos apoptóticos (YUAN et al., 2005). Essas mudanças morfológicas são resultantes da ativação de um grupo de proteases, tais como as caspases (tipos: 1, 2 e 3), existentes nas células como pró-enzimas inativas que, após serem ativadas pela clivagem de resíduos específicos de aspartato, inativam e lisam diversas proteínas, como: a polimerase poli-ADP-ribose (PARP), histona-H1 e proteínas quinases dependentes de DNA (MEN et al., 2003).

O envelhecimento do oócito, após a ovulação, também pode acarretar o rompimento de membranas mitocondriais, ou mesmo a inabilidade de gerar adenosina trifosfato (ATP), e assim tendo consequências negativas sobre a proliferação e a sobrevivência da célula (FISSORE et al., 2002). Os danos mitocondriais promovem colapso do potencial transmembrana da organela e, assim, provoca a separação da cadeia respiratória que cursa com a liberação e a superprodução de ânions superóxidos, interrupção da biogênese mitocondrial, efusão de glutationa e cálcio da matriz e, por fim, a liberação de proteínas transmembrana solúveis que levarão à ativação das caspases e, secundariamente, das endonucleases e a fragmentação do DNA (CUMMINS, 2004).

A indução da fragmentação e da ativação das caspases em oócitos envelhecidos, também pode ser realizada pela sinalização do influxo de íons cálcio por causa da fecundação, sugerindo que este sinal pode atuar como indutor de apoptose. Contudo, desconhece-se como o mesmo sinal pode responder por vias diferentes, ou seja, ativação e morte oocitária. No entanto, é sabido que a mudança da homeostase do cálcio está associada à necrose celular e apoptose em oócitos envelhecidos (FISSORE et al., 2002).

A base molecular para a regulação anômala de cálcio precisa ser melhor elucidada, porém, aparentemente, envolve a redução na concentração de trifosfato de adenosina (ATP), e concomitante à redução da expressão da proteína anti-apoptótica (Bcl-2) em oócitos envelhecidos. A baixa disponibilidade de ATP pode diminuir o funcionamento da bomba do sistema cálcio-ATPase do retículo sarcoplasmático (SERCA), que é responsável pelo preenchimento do retículo endoplasmático (ER). A quantidade reduzida de Bcl-2 pode, negativamente, impedir a função do SERCA, embora a sua função na homeostase do cálcio permaneça controversa. O mau funcionamento do sistema cálcio-ATPase do retículo sarcoplasmático, pode ser o responsável pela homeostase anormal do cálcio em oócitos envelhecidos (FISSORE et al., 2002).

Outro ponto essencial de atuação do cálcio é quanto aos grânulos corticais que durante a ativação do oócito, com o decorrer do envelhecimento pós-ovulatório, tornam-se intumescidos e se mantêm mais profundos no córtex dele. Deste modo, não se fundem com a membrana plasmática e, consequentemente, não ocorre a liberação do conteúdo cortical no espaço perivitelínico. Nesta condição, a exteriorização do conteúdo dos grânulos corticais não se segue à ativação e, com isto, o bloqueio à polispermia não é induzido e o oócito permanece sob risco da ocorrência de polispermia (HUNTER, 1990). 
De forma geral, os oócitos envelhecidos exibem redução das quinases meióticas, do fator promotor de maturação (MPF) e da proteína quinase mitogênica ativada (MAPK), decréscimo na concentração de proteínas antiapoptóticas e dos estoques de íons cálcio do retículo endoplasmático. Também, apresentam função mitocondrial suprimida e liberação de produtos pró-apoptóticos, após a estimulação pelo cálcio (GORDO et al., 2002). Desta maneira, mesmo que o oócito, posteriormente, seja penetrado por um espermatozoide, a fecundação e a formação normal do zigoto com o correto número de cromossomos (diploide) pode não se realizar e, assim, ocorrer a morte embrionária precoce (HUNTER, 1990).

Além do envelhecimento do oócito após a ovulação pela falta do fator inibidor da meiose, o aumento da idade materna, principalmente na espécie humana (BUKVIC et al., 2001), está associado à deterioração na qualidade do oócito. Poucos estudos têm tratado deste assunto em animais domésticos. Contudo, é ponto comum entre os trabalhos nessa área que oócitos envelhecidos desenvolvem disjunção cromossômica anormal, classificada como aneuploidia, definida como o número anormal de cromossomos que não possui um múltiplo exato do número haploide (BALL, 2000). Os fatores e os mecanismos etiológicos responsáveis pelo aumento dos erros na distribuição dos cromossomos durante a formação das células germinativas, ainda não são totalmente conhecidos, podendo sua ocorrência ser distribuída entre os estádios iniciais de formação das células germinativas e meiose no embrião, durante o período da parada meiótica do oócito, antes da retomada da maturação, próximo à senilidade reprodutiva da fêmea, durante a maturação do oócito, antes da fecundação e na meiose II (BAIRD et al., 2005).

Dentre todas as possibilidades de distribuição da ocorrência, a teoria mais aceita é de que os erros meióticos maternos que, preferencialmente, ocorrem durante a primeira divisão meiótica (MI) são os responsáveis pela maioria das aneuploidias (PELLESTOR et al., 2006). Existem vários padrões de segregação anormal da MI: (i) não-disjunção "verdadeira", na qual os homólogos são transportados em conjunto para o mesmo polo celular; (ii) não-disjunção "aquiasmática", na qual homólogos que falham no pareamento e/ou reagrupamento são transportados, independentemente, ao mesmo polo; e (iii) separação prematura das cromátides irmãs (PSSC) que, no lugar dos homólogos, segregam uma da outra. A não-disjunção, na segunda divisão meiótica (MII), resulta da falha das cromátides irmãs em se separarem (BAIRD et al., 2005).

A não-disjunção dos cromossomos bivalentes e a separação prematura das cromátides irmãs têm sido incriminadas como sendo os principais mecanismos de ocorrência de aneuploidia. Alguns autores (ANGELL; XIAN; KEITH, 1993) têm identificado a pré-divisão das cromátides como a principal fonte de aneuploidia entre oócitos. Outros estudos têm sugerido que apesar dos dois erros da meiose I estarem envolvidos na incidência de aneuploidia, a separação pré-matura das cromátides é relatada como artefato de cultura (ZHIVKOVA et al., 2007).

Alguns estudos demonstraram que a frequência do cruzamento entre as cromátides (quiasma) reduz com o avançar da idade materna e a frequência de bivalentes com terminais quiasmáticos é muito maior em oócitos provenientes de fêmeas com maior idade. O decréscimo na frequência de quiasmas é acompanhado pelo aumento da produção de univalentes, que são responsáveis pela não-disjunção e que podem estar correlacionados com os distúrbios de fuso (PLACHOT, 2003). Assim, a formação do fuso poderá ser comprometida, provavelmente pelo desafio metabólico sofrido pelo oócito ou pelos seus precursores durante o longo período de descanso no estádio dictiado no ovário, antes da retomada da maturação, uma vez que esta pode ser, diretamente, afetada pela redução do pH interno (EICHENLAUBRITTER, 1998). O envelhecimento intraovariano do oócito pode comprometer a habilidade do aparato meiótico em balancear adequadamente a segregação cromossômica (PLACHOT, 2003).

O erro do balanceamento cromossômico pode levar à falha na fecundação e na implantação, consequentemente ocasionando perda embrionária e aborto em diferentes estádios da gestação (ARMSTRONG, 2001). Estudos comparativos entre oócitos de éguas velhas e potras demonstraram que a aneuploidia pode estar associada a diferenças morfológicas citoplasmáticas secundárias, sendo que os oócitos de éguas mais velhas apresentam atraso na maturação da metáfase II (AGUIAR et al., 2002). Estes oócitos possuem menor área ocupada pelos grânulos corticais, maior área ocupada pelo retículo endoplasmático liso e maiores vesículas citoplasmáticas por oócito, indicando aumento da incidência de defeitos degenerativos (ARMSTRONG, 2001). 
A atuação da aneuploidia sobre o atraso na maturação do oócito pode estar relacionada, principalmente, com a atividade do MPF e da MAPK (BERTAGNOLLI et al., 2004). A atividade dessas quinases é conduzida pela fosforilação/defosforilação, degradação e síntese de proteínas, além de ser, propriamente, dependente do estado do citoesqueleto do fuso no oócito. A análise dos padrões de fosforilação de proteínas em oócitos de camundongos, estacionados no estádio dictiado, provê evidências preliminares sobre a alteração da síntese e ou fosforilação de proteínas no oócito de fêmeas de maior idade. Desta maneira, isto sugere uma relação causal entre fosforilação alterada, atividade das quinases, regulação do ciclo celular e predisposição à aneuploidia (EICHENLAUB-RITTER, 1998).

Estudo conduzido em camundongos sobre a atividade da MAP quinase e da MPF registrou que a progressão precoce da anáfase I, em oócitos de fêmeas senis, é acompanhada pela queda precoce na atividade da MPF, quando o primeiro corpúsculo polar é formado. Inicialmente, as atividades de ambas as quinases foram menores nos oócitos de animais mais velhos (EICHENLAUB-RITTER, 1998). Aparenta ser substancial que, em oócitos de éguas idosas, esta redução seja secundária ao aumento da incidência de aneuploidia, apesar de carecer de comprovação (BALL, 2000).

Em equinos, apesar da carência de comprovação do envolvimento da aneuploidia na perda embrionária precoce, alguns estudos registraram diferenças na taxas de gestação entre oócitos de éguas jovens e idosas (BALL, 2000). Assim, a taxa de aneuploidias pode ser maior em éguas de idade mais avançada e, até mesmo, apresentar maior incidência do que em humanos. Independentemente dos efeitos da tuba uterina e das patologias uterinas, a maior taxa de subfertilidade em éguas mais velhas poderia ser consequência da fecundação de oócitos que não passaram por uma adequada maturação meiótica, bem como pela maior prevalência de anormalidades cromossomais. Isto porque foi demonstrado que o oócito de éguas mais velhas requer maior período de tempo para maturar até a segunda metáfase, se comparado com o oócito de éguas mais jovens (BRINSKO; BALL; ELLINGTON, 1995).

Em adição, a formação do fuso meiótico, mitótico e a segregação cromossômica por serem processos ativos, dependentes da energia gerada pelas mitocôndrias, sugere-se que o impedimento da função mitocrondial seja a principal causa do aumento da incidência de anormalidades cromossômicas em embriões de fêmeas mais velhas. Durante o crescimento e a maturação do oócito, o número de mitocôndrias aumenta de dezenas para centenas, no estádio de folículo primordial, e de centenas para milhares no momento da ovulação. Neste ponto, a replicação mitocondrial do oócito interrompe e, em camundongos, não se reinicia até o início do estádio de gastrulação do embrião. Como resultado, o início da divisão celular embrionária exige o envolvimento de um elevado número de mitocôndrias derivadas do oócito (RAMBAGS et al., 2006).

Sugere-se que, em éguas velhas, uma espécie de oxigênio reativo, gerado durante a fosforilação oxidativa constitutiva, causaria danos cumulativos sobre a membrana mitocondrial do oócito. No entanto, essa lesão só se torna aparente quando a demanda de energia pelo oócito é maior, por exemplo, durante a maturação in vitro. A redução do número de mitocôndrias e da qualidade de oócitos maturados de éguas velhas pode ter um consequente efeito sobre a competência do seu desenvolvimento (ARMSTRONG, 2001). Em mulheres, o baixo número de cópias do DNA mitocondrial (mtDNA) do oócito tem sido associado com a baixa fertilidade, enquanto em camundongos, grandes danos à mitocôndria do oócito, restringe-se a habilidade deste em sofrer a quebra da vesícula germinal, a formação do fuso meiótico, a segregação dos cromossomos, a extrusão do corpúsculo polar e a formação do blastocisto (RAMBAGS et al., 2005).

Baseando-se nos estudos conduzidos até o presente momento, aparentemente os defeitos do oócito (seja por elevar a incidência de aneuploidia ou por erros da cópia do mtDNA) são as causas mais prováveis do aumento das perdas reprodutivas em éguas mais velhas (BALL, 2000; ARMSTRONG, 2001) e humanos (EICHENLAUB-RITTER, 1998). Isto representa somente a menor parte, se comparado à redução na capacidade de desenvolvimento. Deste modo, as condições pregressas, às quais o oócito foi submetido durante o desenvolvimento e na vida reprodutiva, são determinantes da sua qualidade. A aneuploidia aumenta com o avançar da idade, mas não é a causa exclusiva da redução da fertilidade. É essencial caracterizar e identificar a causa da menor qualidade dos oócitos de animais velhos, uma vez que isto poderá gerar maiores informações sobre o estudo etiológico da aneuploidia e sua relação com o avançar da idade (EICHENLAUB-RITTER, 1998). 


\section{CONSIDERAÇÕES FINAIS}

Oócitos envelhecidos apresentam mitocôndrias com anomalias genéticas e morfológicas, sendo que suas consequências ainda precisam ser melhor compreendidas. Entretanto, estes oócitos são mais sensíveis às lesões mitocondriais em relação aos de ovulação mais recente, porém possuem respostas metabólicas e apoptóticas similares. Estes defeitos, aparentemente, são as causas mais prováveis do aumento da perda reprodutiva em fêmeas mais velhas. Todavia, de algum modo, isto representa somente a menor parte, quando comparado à reduzida capacidade de desenvolvimento. Esses e futuros achados podem contribuir para aperfeiçoar as estratégias laboratoriais para minimizar as injúrias nos oócitos e melhorar as perspectivas para as taxas de concepção.

\section{REFERÊNCIAS}

AGUIAR, J. J. et al. Nuclear, cytoplasmic and mitochondrial patterns of ovulated oocytes in young and mares. Theriogenology, Amsterdam, v. 58, n. 2/4, p. 689-692, 2002.

ANGELL, R. R.; XIAN, J.; KEITH, J. Chromosome anomalies in human oocytes in relation to age. Human Reproduction, London, v. 8, n. 7, p. 1047-1054, 1993.

ARMSTRONG, D. T. Effects of maternal age on oocyte developmental competence. Theriogenology, Amsterdam, v. 55, n. 6, p. 1303-1322, 2001.

BAIRD, D. T. et al. Fertility and ageing. Human Reproduction Update, London, v. 11, n. 3, p. 261-276, 2005.

BALL, B. A. Reduced reproductive efficiency in the aged mare: role of early embryonic loss. In: INTERNATIONAL VETERINARY INFORMATION SERVICE. Recent advances in equine theriogenology. 2000. Disponível em: < http://www.ivis.org/ proceedings/AAEP/2000/ contents.pdf.> Acesso em: 02 set. 2006.

BERTAGNOLLI, A. C. et al. Interação entre células do cumulus e atividade da proteína quinase C em diferentes fases da maturação nuclear de oócitos bovinos. Arquivo Brasileiro de Medicina Veterinária e Zootecnia, Belo Horizonte, v. 56, n. 4, p. 488-496, 2004.

BLUE, M. G. A cytogenetical study of prenatal loss in the mare. Theriogenology, Amsterdam, v. 15, n. 3, p. 295-309, 1981.

BRINSKO, S. P.; BALL, B. A.; ELLINGTON, J. E. In vitro maturation of equine oocytes obtained from different age groups of sexually mature mares. Theriogenology, Amsterdam, v. 44, n. 4, p. 461-469, 1995.

BUKVIC, N. et al. Sex chromosome loss, micronuclei, sister chromatid exchange and aging: a study including 16 centenarians. Mutation Research, Amsterdam, v. 498, n. 1/2, p. 159-167, 2001.

CUMMINS, J. M. The role of mitochondria in the establishment of oocyte functional competence. European Journal of Obstetrics \& Gynecology and Reproductive Biology, Amsterdam, v. 115S, p. 23-29, 2004. Supplement 1.

EICHENLAUB-RITTER, U. Genetics of oocyte ageing. Maturitas, Amsterdam, v. 30, n. 2, p. 143-169, 1998.

FISSORE, R. A. et al. Mechanisms underlying oocyte activation and postovulatory ageing. Reproduction, London, v. 124, n. 6, p. 745-754, 2002. 
GORDO, A. C. et al. Intracellular calcium oscillations signal apoptosis rather than activation in in vitro aged mouse eggs. Biology of Reproduction, Washington, v. 66, n. 6, p. 1828-1837, 2002.

HUNTER, R. H. F. Gamete lifespans in the mare's genital tract. Equine Veterinary Journal, London, v. 22, n. 6, p. 378-379, 1990.

MEN, H. et al. Degeneration of cryopreserved bovine oocytes via apoptosis during subsequent culture. Cryobiology, Amsterdam, v. 47, n. 1, p. 73-81, 2003.

PELLESTOR, F. et al. The occurrence of aneuploidy in human: lessons from the cytogenetic studies of human oocytes. European Journal of Medical Genetics, Amsterdam, v. 49, n. 2, p. 103-116, 2006.

PLACHOT, M. Genetic analysis of the oocyte: a review. Placenta, Amsterdam, v. 24, n. 2, p. 6669, 2003.

RAMBAGS, B. P. B. et al. Oocyte mitochondrial degeneration during reproductive ageing in the mare. In: INTERNATIONAL EQUINE GAMETE GROUP, 18., 2005, Germany. Proceedings... Germany: Kühlungsborn, 2005. p. 25-27.

Maturation in vitro leads to mitochondrial degeneration in oocytes recovered from aged but not young mares. Animal Reproduction Science, Amsterdam, v. 94, n. 1-4, p. 359-361, 2006.

SALTZMAN, A. A. Insemination of mares after ovulation. Animal Breeding Abstracts, London, v. 8, n. 1, p. 16-20, 1940.

ZHIVKOVA, R. S. et al. Analysis of human unfertilized oocytes and pronuclear zygotes - Correlation between chromosome/chromatin status and patient-related factors. European Journal of Obstetrics \& Gynecology and Reproductive Biology, Amsterdam, v. 130, n. 1, p. 73-83, 2007.

YUAN, Y. Q. et al. Apoptosis in cumulus cells, but not in oocytes, may influence bovine embryonic developmental competence. Theriogenology, Amsterdam, v. 63, n. 8, p. 2147-2163, 2005.

WOODS, J. et al. Effects of time of insemination relative to ovulation on pregnancy rate and embryonic loss in mares. Equine Veterinary Journal, London, v. 22, n. 6, p. 410-415, 1990.

Recebido: 04/10/2008

Received: 10/04/2008

Aprovado: 20/03/2009

Approved: 03/20/2009 